\title{
Developing Healthcare Leaders, Fostering Collaboration, and Facilitating Transformation in the Kingdom of Saudi Arabia: Practice-Based Synthesis Projects in a Global Executive Graduate Program
}

\section{Celaya, Leandra Y. ${ }^{\text {a }}$; Mueller, Daniel K. ${ }^{\mathrm{b}}$ and Hernandez, S. Robert ${ }^{\mathrm{c}}$}

${ }^{a}$ Department of Health Services Administration, University of Alabama at Birmingham, United States of America, ${ }^{b}$ Department of Health Services Administration, University of Alabama at Birmingham, United States of America ${ }^{c}$ Department of Health Services Administration, University of Alabama at Birmingham, United States of America.

\begin{abstract}
At the 2015 International Hospital Federation (IHF) World Congress in Chicago, Illinois, USA, the Global Consortium for Healthcare Management Professionalization presented a call to action to professionalize the field of healthcare management. Governments and organizations that seek to realize the benefits of professional healthcare managers may meet this challenge by providing educational opportunities to established executives who are positioned to lead and ultimately mentor future managers. This paper presents a case example of an executive graduate program in health administration, delivered by a university in the United States in partnership with the Ministry of Health in Saudi Arabia, with the aim of developing Saudi healthcare professionals as healthcare leaders. We share challenges, experiences and insights related to adapting a US curriculum for the Saudi working executives during a time of transformation in the Kingdom. We also provide a detailed description of the Executive Management Study, an applied synthesis activity required for all executive learners in the program. Results of an alumni survey are incorporated to demonstrate graduates' perceptions of the effectiveness of the learning experience.
\end{abstract}

Keywords: healthcare management education; executive education; synthesis projects; team-based learning; project-based learning; global graduate education. 


\section{Introduction}

At the 2015 International Hospital Federation (IHF) World Congress in Chicago, Illinois, USA, the Global Consortium for Healthcare Management Professionalization presented a call to action to professionalize the field of healthcare management. The consortium, consisting primarily of professional associations and academics from around the globe, argued that "enhancing the management capacity of individual leaders and teams" has been shown to improve the quality of healthcare services and to lead to better use of resources (International Hospital Federation [IHF], 2015). Recognizing the growing need to improve the skills, depth of knowledge, and competencies for healthcare managers and leaders worldwide, they suggest that governments and health systems will need to invest in training and education if they wish to realize the benefits of professional management.

For decades in the United States, the master's degree in health administration has served as an entry requirement for healthcare management positions. However, it is common practice in many countries for clinicians to be promoted to healthcare management positions having never received formal training or education in management or leadership (Hernandez, O'Connor, \& Meese, 2018). Clinicians who are promoted to leadership positions often learn on the job, facing a complex environment where resources are often scarce and demand for high quality, efficient care is pervasive.

Governments and organizations that seek to realize the benefits of professional healthcare managers may meet this challenge by providing educational opportunities to established executives who are positioned to lead and ultimately mentor future managers. One country where such efforts were recently undertaken is the Kingdom of Saudi Arabia (KSA). A major transformation in all sectors of government (including the Ministry of Health), a lack of sufficient formal educational programs in healthcare management, compounded by a countrywide effort to invest in education as a "means of reducing Saudi Arabia's dependence on expatriate staff" (Eckstein, et al, 2003), led to a strategic decision to collaborate with a university in the United States to develop a customized graduate program to develop Saudi leaders.

With the broad goal of ensuring the future success and sustainability of the healthcare delivery system in KSA, health system leaders and administrators from the American university designed a program for professionals who are in positions where they can immediately apply the knowledge they are gaining in the classroom to real world situations. Choosing the appropriate content and method of delivery for formal education or training can prove challenging, especially when facing a variety options for pedagogical approaches such as classroom instruction, skill-based training, challenging job assignments, team training, action learning, feedback, mentoring, and coaching (Landry \& Bewley, 2009). 
Rather than selecting one approach, program leaders recognized the value of integrating a variety of pedagogical approaches.

Furthermore, as Scott argues, learning in the $21^{\text {st }}$ century must move beyond traditional lecture models to more engaging and applied methods. "To develop the higher-order skills they now need, individuals must engage in a meaningful enquiry-based learning that has genuine value and relevance for them personally and their communities" (Scott, 2015). In addition to action learning assignments throughout the curriculum, a structured Executive Management Study (EMS) was designed as a practice-based synthesis activity, requiring learners to develop creative solutions to real-time challenges in the Saudi health system.

The purpose of this paper is to provide a case example of cross-culutral collaboration in higher education; and, specifically, to share experiences and preliminary outcomes of the applied synthesis projects in a global graduate degree program for healthcare executives in the Kingdom of Saudi Arabia. A post-graduation survey was administered to all 64 graduates to evaluate attitudes and feelings regarding the program. Most questions were evaluated on a five-point Likert scale, with five being the most favorable response and one being the least favorable response. We highlight specific findings (from 22 respondents) in section three of this paper.

\section{Program Description and Key Challenges}

\subsection{Adapting the Curriculum}

An initial challenge facing the American university was to adapt a US-based healthcare management curriculum to be appropriate for the Saudi educational environment. The main objective was to design the curriculum based on the roles that executive graduates would assume after completing their degree. The curriculum needed to incorporate the specific knowledge, skills, and abilities that future KSA leaders would use to overcome challenges facing their healthcare system.

To tailor the curriculum to be appropriate in KSA, American faculty members engaged in detailed discussions with Saudi healthcare leaders and administrators to learn more about hospital and health system operations in Saudi Arabia. Saudi leaders offered valuable input regarding relevant topics in specific courses such as Finance, Human Resources, and Health Policy. A Saudi attorney who was familiar with both US and Sharia Law co-taught the Health Law course, and the Marketing course was adapted to focus more on managerial epidemiology than on topics important in the competitive US healthcare environment.

Furthermore, it was important for the executive education design to differ from traditional lecture-based methods in order to be valuable for professionals. Traditional approaches 
emphasize rote memorization and the application of simple educational procedures, which do not enhance critical thinking skills or student-directed learning. Teaching strategies, especially for the executive learner, must include a problem-based educational model (Donnelley, 2017). In addition, the curriculum needed to be sensitive to the concerns of teaching across cultures, to prepare Saudi medical professionals to cope with the challenges facing healthcare, and to improve their readiness for implementing changes that would later be defined by the 2030 Healthcare Transformation Strategies ("Saudi Vision 2030", 2018).

\subsection{The Blended-Delivery Model}

To meet the needs of executives who would maintain their full-time employment while undertaking a graduate degree program, the Executive Master of Science in Health Administration (EMSHA) combined traditional classroom instruction and online digital media. This blended-delivery approach required faculty members and learners to participate in didactic presentations, along with guided on-line media interventions and mentored group activities. American faculty members traveled to Saudi Arabia for on-site sessions once each semester, delivering approximately 20 contact hours per course in a face-to-face format. On-site sessions were complemented by online group lectures, studentled team projects, concept-based group discussions and applied course assignments.

While the American university has successfully delivered domestic programs for working executives since the 1990's, the global nature of the EMSHA program presented several unique challenges. Time zone differences, differences in the scheduled workweek, longdistance travel requirements for faculty, and technology support were just a few of the barriers to executing the blended-delivery format of the program from the US to KSA.

\subsection{The Executive Management Study Timeline and Process}

A critical element of the curriculum was the EMS, which was designed to serve as a synthesis activity during the second year of the two-year program. The EMS projects employed practiced-based learning, which afforded executive learners the opportunity to identify healthcare problems plaguing service delivery in KSA and to work in multidisciplinary, dual-gender teams to study and suggest innovative solutions (Furman and Sibthorp, 2013). The components of the EMS required learners to integrate concepts from most courses in the curriculum. Work spanned approximately nine months to allow time for concept development, coaching feedback, and schedule adaptation around the holy month of Ramadan.

Projects were based on real-world issues and were designed to address problems of relevance and importance to the executive learners and their organizations. Initially, many suggested projects were very broad in scope and scale. Faculty coaches guided learners to construct clear, concise problem statements and often intervened to assist the teams in 
breaking down larger tasks into smaller, more manageable pieces. This helped the teams to better define targeted solutions and produce a more realistic time lime for implementation.

The following outline lists sequential steps for implementing an EMS. Over the course of two executive cohorts in KSA, this timeline has been revised to better facilitate the learning process and to adjust for work expectations during Ramadan and other religious holidays.

Table 1. EMS Structure and Nine-Month Timeline

\begin{tabular}{ccc}
\hline Timeframe & Activity & Deliverable \\
\hline Early Month 1 & Identify topics, select teams, and meet with faculty coach to & \\
finalize topic proposal & \\
End of Month 1 & Meet with CEO/senior leader to present topic for approval & $\mathrm{X}$ \\
Early Month 2 & Meet with Faculty Coach to discuss project plan & \\
End of Month 2 & EMS Chapter 1: Intro, Problem Statement and Justification Due & $\mathrm{X}$ \\
Early Month 3 & EMS Chapter 2: Literature Review Draft Due & $\mathrm{X}$ \\
Mid-Month 3 & Faculty Coach Review Meeting & \\
Early Month 4 & EMS Chapter 3: Methodology Due & $\mathrm{X}$ \\
End of Month 6 & EMS Chapter 4: Results Due & $\mathrm{X}$ \\
Early Month 8 & EMS Chapter 5: Results and Recommendations Due & $\mathrm{X}$ \\
Early Month 9 & Submit written report and virtual oral presentation to faculty & $\mathrm{X}$ \\
Mid-Month 9 & Incorporate feedback and revise & \\
Late Month 9 & Final oral presentation to senior leadership team & $\mathrm{X}$ \\
\hline
\end{tabular}

\section{Strategies and Outcomes}

\subsection{Developing Leaders}

A key driver behind the establishment of the EMSHA program in KSA was the desire by the Ministry of Health to develop competent Saudi healthcare leaders and, ultimately, reduce the reliance on expatriates in administrative positions. The EMSHA program and, particularly, the EMS provided opportunities to develop leaders in a variety of ways.

Stefl (2008) described the important role that executives play in providing a clear understanding of the healthcare organizational vision and mission to engage their leadership team in programmatic development. As an experiential, problem-based learning exercise that involved application to real-world projects, the EMS gave learners an opportunity to develop programs that engaged colleagues and demonstrated their leadership 
abilities. Senior leaders, such as the hospital CEO and senior executive team, provided guidance and consultation to ensure that project topics directly aligned with the organizational vision and mission and delivered direct value to the organization.

The Global Healthcare Management Competency Directory lists analyzing problems, promoting solutions, and encouraging decision-making as a leadership competency that healthcare managers should possess (IHF, 2015). Others have argued that executives need skills in critical thinking, effective communication, and innovative problem-solving (Tsasis, et. al., 2013); and Kovner \& D'Aunno (2017) stressed the importance of developing healthcare leaders who can employ evidence-based management skills to improve the decision-making processes in their organizations.

The project-based learning design of the EMS required executive learners to analyze and define problems, to reason using clear arguments and communicate their ideas effectively, to use evidence in their decision-making, and to propose inventive implementation strategies. As a result, they further developed a number of important leadership abilities and behaviors. In fact, more than $86 \%$ of respondents to the alumni survey stated that the EMSHA program had an above average effect on improving both their ability to communicate their ideas to others throughout their organizations and on their ability to make evidence-based decisions.

\subsection{Fostering Collaboration}

The EMS fostered collaboration amongst Saudi executive learners through the multidisciplinary, team-based approach. Teams often included physicians, nurses, and administrators working across silos to accomplish the objectives of the project. Most graduates $(86 \%)$ perceived a high level of value from the multidisciplinary team design of the EMS. In addition, the opportunity to collaborate and work as a team was specifically and repeatedly cited as a major benefit of the EMS experience.

The dual-gender team design also offered a unique opportunity for men and women to collaborate in an educational environment. Traditionally, education in Saudi Arabia is segregated by gender (Smith \& Abouammoh, 2013). Healthcare, however, is a professional environment where men and women from a variety of cultural backgrounds work side-byside to care for patients. At the beginning of the EMSHA program in 2012, the sponsoring institution and the American university received special permission to hold classes in an unrestricted (meaning there would be no dividers or barriers in the room) dual-gender setting and for the EMS teams to be comprised of both men and women.

The goal of the program was not to impose Western values in the Saudi educational environment. Rather, program and hospital leaders recognized how imperative it is for men and women from various disciplines to collaborate to solve problems in health care. 
The EMS provided a chance for developing collaborative professional relationships that transfer from the educational environment to the workplace.

\subsection{Facilitating Transformation}

The vast transformation currently taking place in the health system in Saudi Arabia requires leaders who are better prepared for problem solving and for implementation of changes that have the potential to improve healthcare organizations and healthcare delivery. All survey respondents stated that the program improved their ability to apply their newly acquired knowledge of health administration to propose creative solutions to challenges. In addition, the EMS projects presented opportunities for learners to make an impact on healthcare delivery and the health system as a whole in Saudi Arabia.

EMSHA students gained support for their projects from senior leaders prior to beginning the EMS process and presented their work and findings to senior leaders at the conclusion of the program. This was an important step toward ensuring the possibility for implementation. Despite major change during this time of transformation and somewhat restricted access to funding, approximately $64 \%$ of survey respondents said it was likely that their team's EMS would be implemented.

EMS projects such as, "Reducing cardiac mortality during Hajj Season: the largest gathering on the planet" and "A proposal to establish a Saudi equivalent of the National Institute of Health" are already underway and have the potential to make a broad impact on the Kingdom. Other projects such as, "The effectiveness of recruitment strategies and the severity of barriers of staff nurses in a selected tertiary care hospital in the Kingdom of Saudi Arabia" and "Proper utilization of an out-patient department at (a specialty care hospital in Saudi Arabia)" are being implemented to make improvements in strategic areas for one particular hospital. However, these projects have the potential to be replicated in other organizations throughout the Kingdom.

\section{Conclusion}

In conclusion, the EMSHA program and, particularly, the EMS experience have provided several opportunities for developing leaders, fostering collaboration, and facilitating healthcare transformation in Saudi Arabia. There is more work to be done in terms of refining the program and measuring outcomes, but projects are already making an impact in the Kingdom. Now, many of the recent graduates are utilizing their acquired administrative and management skills to lead the changing healthcare environment to better serve its citizenry. 


\section{References}

Donnelly, R. (2017). Blended Problem-Based Learning in Higher Education: The Intersection of Social Learning and Technology. Psychosociological Issues in Human Resources Management. 5(2): 25-50.

Eckstein, L.K., et. al. (2003). Understanding Your International Students: An Educational, Cultural, and Linguistic Guide. J. Flaitz (Ed). Ann Arbor, MI: The University of Michigan Press.

Furman, N. and Sibthorp, J. (2013). Leveraging Experiential Learning Techniques for Transfer. New Directions for Adult and Continuing Education, (137), 17-26.

Hernandez, S. R, O'Connor, S. J., and Messe, K. (2018). Global Efforts to Professionalize the Healthcare Management Workforce: The Role of Competencies. Manuscript submitted for publication.

International Hospital Federation. (2015). Leadership Competencies for Health Services Managers. Bernex, Switzerland.

Kovner, A. R., \& D'Aunno, T. A. (2017). Evidence-Based Management in Healthcare (2nd ed.). Chicago: Health Administration Press.

Landry, A. Y., \& Bewley, L. W. (2009). Leadership Development, Succession Planning, and Mentoring. Strategic Human Resources Management in Health Services Organizations, 133-146.

Saudi Vision 2030. (2018) National Transformation Program 2020. Retrieved from: http://vision2030.gov.sa/en/ntp

Scott, C. L. (2015). The Futures of Learning 3: What Kind of Pedagogies for the 21st Century? UNESCO Education Research and Foresight, Paris. ERF Working Papers Series, No. 15.

Smith, L. and Abouammoh, A. (2013). Higher Education in Saudi Arabia: Achievements, Challenges, and Opportunities. Dordrecht: Springer Netherlands.

Stefl, M. E. (2008). Common competencies for all healthcare managers: the Healthcare Leadership Alliance model. J Healthc Manag, 53(6), 360-373; discussion 374.

Tsasis, P. et al. (2013). Learning to Learn: Toward a Relational and Transformational Model of Learning for Improved Integrated Care Delivery. Administrative Science, $3(2) ; 9-13$. 